\title{
Decreased Phosphorylation of NMDA Receptor Type 1 at Serine 897 in Brains of Patients with Schizophrenia
}

\author{
Effat S. Emamian, ${ }^{1,2}$ Maria Karayiorgou, ${ }^{1}$ and Joseph A. Gogos ${ }^{2}$ \\ ${ }^{1}$ The Rockefeller University, Laboratory of Human Neurogenetics, New York, New York 10021, and ${ }^{2}$ Columbia University, College of Physicians and \\ Surgeons, Department of Physiology and Cellular Biophysics, Center for Neurobiology and Behavior, New York, New York 10032
}

\begin{abstract}
NMDA receptor hypofunction in schizophrenia has been inferred by a large number of clinical and preclinical observations; however, whether and how NMDA receptors are exactly involved in the pathogenesis of schizophrenia are still unknown and subject to interpretation. Here we show, in two independent samples of brains from patients with schizophrenia, a significant decrease in the phosphorylation level at serine 897 (S897) of the NMDA receptor type 1 (NR1) subunit. Our finding, together with a previous report that antipsychotics increase phosphorylation of NR1 at S897 in vivo, strongly suggests that insufficient phosphorylation at S897 may contribute to the neuronal pathology underlying schizophrenia.
\end{abstract}

Key words: schizophrenia; NMDA receptors; NR1; phosphorylation; serine 897; postmortem

\section{Introduction}

Two major lines of pharmacological evidence provide indirect support for a role of NMDA receptor hypofunction in schizophrenia. First, administration of noncompetitive NMDA antagonists, such as phencyclidine (PCP) or ketamine, exacerbates psychotic symptoms in schizophrenics and mimics both the positive and negative schizophrenia symptoms in nonpsychiatric controls (Thaker and Carpenter, 2001). Indeed, PCP-induced psychosis is regarded as the best pharmacological model of schizophrenia (Javitt and Zukin, 1991), and animals treated with subanesthetic doses of NMDA receptor antagonists are used to model various aspects of the disease (Kilts, 2001). Second, NMDA receptor agonists at the glycine modulatory site, such as glycine, D-cycloserine, and D-serine, have been shown to improve cognition and decrease negative symptoms in schizophrenic subjects when combined with typical antipsychotics (Tsai et al., 1998; Goff et al., 1999; Heresco-Levy et al., 1999). The implication of altered NMDA receptor function in schizophrenia has prompted investigations designed to examine levels of NMDA receptor ligand binding and mRNA levels of NMDA receptor subunits in brains of schizophrenics with mostly inconsistent results (Meador-Woodruff and Healy, 2000). Moreover, additional genetic studies failed so far to identify mutations or susceptibility variants that are preferentially inherited by patients with schizo-

\footnotetext{
Received 0ct. 14, 2003; revised Dec. 23, 2003; accepted Dec. 27, 2003.

We thank the Medical Research Council Brain Bank and the Stanley Foundation Brain Consortium for providing us with samples. Postmortem brains were donated by the Stanley Foundation Brain Consortium courtesy of Drs. Llewellyn B. Bigelow, Juraj Cervenak, Mary M. Herman, Thomas M. Hyde, Joel E. Kleinman, José D. Paltàn, Robert M. Post, E. Fuller Torrey, Maree J. Webster, and Robert H. Yolken.

Correspondence should be addressed to either of the following: Joseph A. Gogos, Columbia University, College of Physicians and Surgeons, Department of Physiology and Cellular Biophysics, Center for Neurobiology and Behavior 630 West 168th Street, P\&S 11-519, New York, NY 10032, E-mail: jag90@columbia.edu; or Maria Karayiorgou, The Rockefeller University, Laboratory of Human Neurogenetics, 1230 York Avenue, Box 313, New York, NY 10021, E-mail: karayim@rockefeller.edu.

D0I:10.1523/JNEUROSCI.4650-03.2004

Copyright $\odot 2004$ Society for Neuroscience $\quad$ 0270-6474/04/241561-04\$15.00/0
}

phrenia in a consistent manner (Schiffer, 2002). Thus, although schizophrenia, by inference, is likely to be accompanied by a dysregulation of NMDA-mediated signaling, the molecular basis of the dysregulation remains elusive and subject to interpretation. Although protein phosphorylation has been established as an important mechanism for the regulation of NMDA receptor function (Swope et al., 1999), the phosphorylation status of the NMDA receptor subunits has not been assayed in brains of patients with schizophrenia. The NMDA receptor type 1 (NR1) subunit, specifically, is a target for phosphorylation by both protein kinase A, at serine 897 (S897), and protein kinase C, at S896 (Tingley et al., 1997). Intriguingly, it has been shown that antipsychotic drugs have the ability to modulate NMDA receptor function by increasing the phosphorylation of NR1. Treatment with haloperidol has been shown to increase NR1 phosphorylation levels at S897 in vivo in the striatum (other brain regions were not examined), as well as in the neuronal culture system (Leveque et al., 2000). Moreover, a mutation of NR1 S897 to alanine was shown to interfere with haloperidol-mediated gene expression (Leveque et al., 2000).

\section{Materials and Methods}

Protein extraction and Western blot analysis. For protein extraction from the frontal cortex, precisely dissected frozen blocks obtained from the Medical Research Council (MRC) Brain Bank or frozen sections obtained from the Stanley Consortium Brain Bank were homogenized in ice-cold lysate buffer $(0.25 \mathrm{M}$ Tris, $\mathrm{pH} 7.5)$ containing protease inhibitors (Protease Inhibitor Cocktail tablets; Roche, Indianapolis, IN) and phosphatase inhibitor (Phosphatase Inhibitor Cocktails I and II; Sigma, St. Louis, $\mathrm{MO}$ ) and lysed through three cycles of freezing (in liquid nitrogen) and thawing (in $37^{\circ} \mathrm{C}$ water bath). Protein concentration was measured using the Bio-Rad protein assay (Bio-Rad, Hercules, CA) and spectrometry at $595 \AA$. Equal amounts of total proteins were loaded on $4-12 \%$ gradient Bis-Tris gels, run using the NuPAGE system (Invitrogen, Carlsbad, CA), and transferred onto nitrocellulose membranes (Schleicher \& Schuell, Keene, NH). Membranes were probed with primary phosphospecific antibodies [S897 phospho-NR1, and S831 and S845 phospho- 
glutamate receptor 1 (GluR1) (Upstate Biotechnology, Waltham, MA) and S380 phosphophosphatase and tensin homolog deleted from chromosome 10 (PTEN) (Cell Signaling, Beverly, MA)], as well as with anti-NR1 (PharMingen, Los Angeles, CA) and anti-tubulin (Sigma) followed by secondary antibodies (Amersham Biosciences, Arlington Heights, IL). Signals were detected by chemiluminescence (PerkinElmer Life Sciences, Boston, MA) followed by autoradiography.

Phosphatase treatment. Equal amounts of total protein from the protein extracts of human frontal cortex were resuspended in appropriate phosphatase reaction buffers (for lambda phosphatase: 500 mм HEPES, pH 7.5, 1 mм EDTA, 20 $\mathrm{mm} \mathrm{MnCl}_{2}$, and $5 \mathrm{~mm}$ DTT; for protein phosphatase (PP) 1 and PP2A: $0.15 \mathrm{M} \mathrm{NaCl}, 20 \mathrm{~mm}$ MOPS (3-(N-morpholino)propanesulfonic acid) $\mathrm{pH}$ 7.5, $60 \mathrm{~mm}$ 2-mercaptoethanol, $0.1 \mathrm{~mm} \mathrm{MnCl}_{2}, 1$ $\mathrm{mm} \mathrm{MgCl}_{2}, 1 \mathrm{~mm}$ EGTA, $10 \%$ glycerol, and 0.1 $\mathrm{mg} / \mathrm{ml}$ serum albumin). Four hundred units of lambda phosphatase, $1 \mathrm{U}$ of PP1, or $2 \mathrm{U}$ of PP2A (Upstate Biotechnology, Waltham, MA) was added, and all samples, including the controls, were incubated for $30 \mathrm{~min}$ at $30^{\circ} \mathrm{C}$. Reactions were terminated by adding SDS sample buffer, and samples were subjected to Western blot analysis, as described.

Statistical analysis. Means and SDs of relative phosphorylation levels in brain extracts from schizophrenics and controls were compared using either the unpaired two-tailed $t$ test or the Mann-Whitney test, when appropriate. For comparisons involving more than two groups (Stanley Tissue data), nonparametric ANOVA (Kruskal-Wallis Test) was used because Bartlett statistic showed a statistically significant difference in SDs among the four groups.

\section{Results}

To assess whether phosphorylation of NR1 at S897 is impaired in schizophrenia, we used a phospho-specific antibody (Tingley et al., 1997) (referred to hereafter as S897Ab) in postmortem brain tissues obtained from the MRC Brain Bank (London, UK). We first verified the phospho-specificity of S897Ab on human brain tissue. As shown in Figure $1 A$, reactivity of S897Ab is dramatically reduced after treating the human brain lysate with lambda phosphatase or PP2A, confirming the specificity of S897Ab for the phosphorylated form of human NR1. Analysis of frontal cortex lysates did not reveal any differences in the total NR1 protein levels after correcting with $\alpha$-tubulin as loading control. To quantify the relative phosphorylation level of NR1 on S897, the immunoblots prepared from frontal cortex lysates were stripped and reprobed with S897Ab. The ratio of S897 density to total protein density was used as a measure of phosphorylation levels of NR1 at S897 in each subject. In two independent replicate assays on the MRC tissues, we observed a dramatic decrease in the S897/total NR1 ratio in the frontal cortex of schizophrenics compared with controls and good reproducibility of individual ratios [88\% decrease in the first experiment, $p=0.0005$, Mann-Whitney test (Fig. $1 B$ ); 70\% decrease in the second experiment, $p=$ 0.0049 , unpaired $t$ test (data not shown)]. We also tested hippocampal protein extracts with the same antibodies and observed a similarly dramatic decrease in S897/total NR1 in the hippocampus of the schizophrenics compared with controls (99\% decrease; $p=0.01$; Mann-Whitney test) (Fig. 1C). Thus, in agreement with expectations from the previously observed augmentation in S897 phosphorylation by typical antipsychotics, we observed a deficit
B

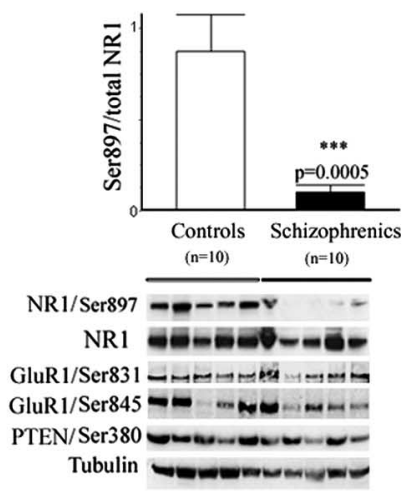

C

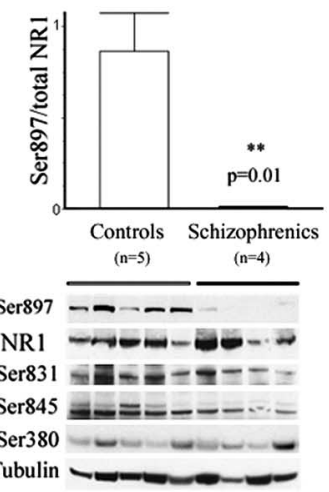

Figure 1. Decreased phosphorylation of NR1 at S897 in postmortem brain tissue obtained from the MRC Brain Bank. A, S897Ab from the MRC Brain Bank. Representative immunoblots are shown, probed with S897NR1 antibody (1:1000), anti-NR1 antibody (1:1000), S831 GluR1 antibody (1:1000), S845 GluR1 antibody (1:1000), S380 PTEN antibody (1:2000), and anti-tubulin (1:1000).

at 8897 phosphorylation in frontal cortex and hippocampus, two of the primary sites of disease pathology.

We followed up our initial observation by attempting to verify reduction of phosphorylation of NR1 at S897 in frontal cortex in an independent sample of postmortem tissues obtained from the Stanley Consortium Brain Bank (Torrey et al., 2000). Tissue obtained from the Stanley Consortium consisted of 10 consecutive frozen sections from rostrocaudally matched areas of frontal cortex from patients diagnosed with schizophrenia, bipolar mood disorder, and major depression, as well as controls subjects. These samples are matched in terms of age, gender, race, postmortem intervals, and the average antipsychotic treatment (Torrey et al., 2000). Protein extracts from cortical lysates were subjected to SDS-PAGE and immunoblot analysis. We initially probed two sets of immunoblots with the protein extracts from all 60 samples, blind to the affected status. In both replicate assays, we observed a decrease in S897/total NR1 in the frontal cortex of schizophrenics compared with controls $[p=0.03$ (Fig. $2 A$ ) and 0.04 (data not shown); nonparametric ANOVA]. Interestingly, the observed decrease was specific to schizophrenia because there were no differences between controls and patients with bipolar mood disorder or major depression (Fig. $2 A$ ). In addition, after release of the sample identifier codes by the Stanley Brain Bank, we repeated the experiments two more times using frontal cortex from patients diagnosed with schizophrenia and control subjects and observed a consistent decrease in S897/total NR1 [79\% decrease in the first experiment, $p=0.01$ (Fig. 2B); $80 \%$ decrease in the second experiment, $p=0.01$ (data not shown), Mann-Whitney test]. In all four experiments on tissues obtained from the Stanley Consortium, a nonsignificant increase was observed in total NR1 levels (corrected to actin or tubulin as loading control) in schizophrenics.

To rule out the effect of confounding factors such as age, gender, postmortem intervals, average antipsychotic uptake, etc., we analyzed separately the correlation of S897/total NR1 with each of these factors using the Pearson correlation analysis on 
A
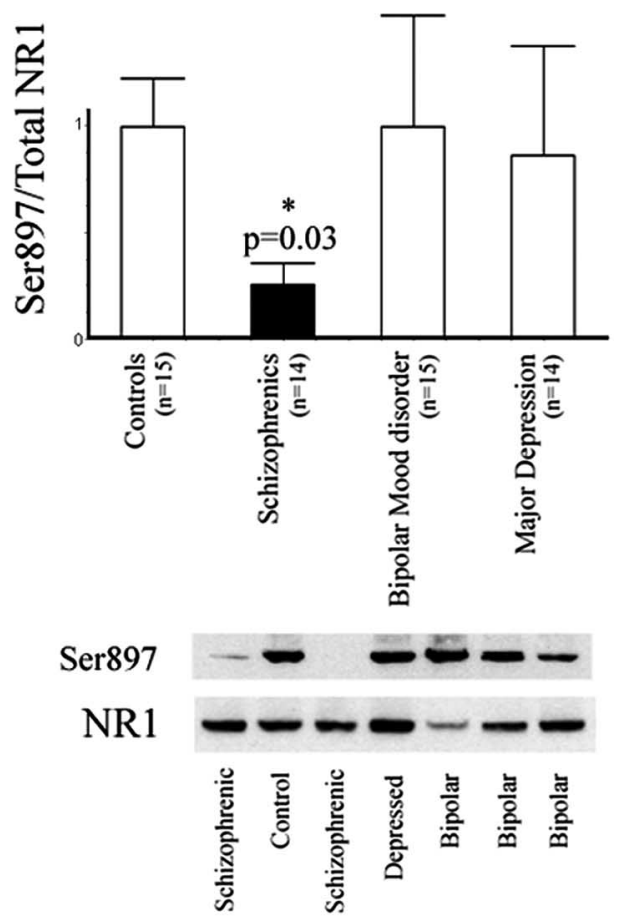

B
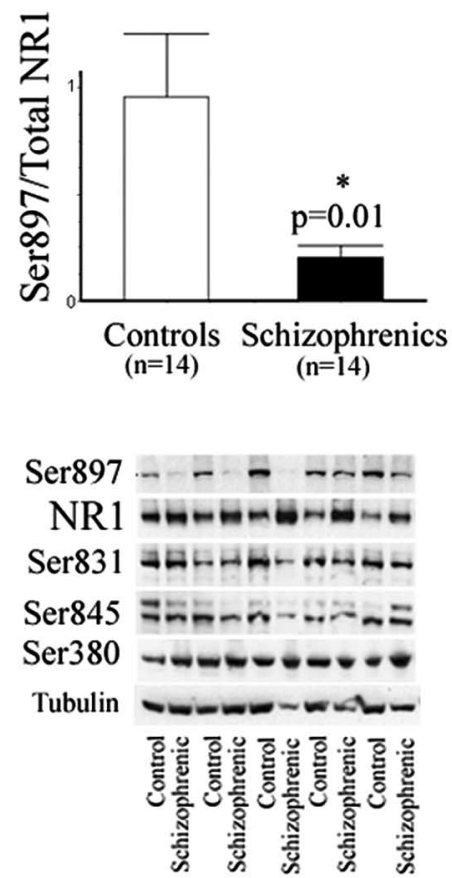

Figure 2. Decreased phosphorylation of NR1 at $\$ 897$ in postmortem brain tissue obtained from the Stanley Brain Bank. $A, B$, Phosphorylation of NR1 on 5897 in frontal cortex of patients with schizophrenia $(n=14)$, bipolar mood disorder $(n=15)$, major depression $(n=14)$, and controls $(n=15)$ obtained from the Stanley Consortium Brain Bank. The decrease in phosphorylation of NR1 on $\mathbf{8} 897$ is specific to patients with schizophrenia. Fifty micrograms of total protein extract were loaded in each lane, and samples were examined blind to the affected status $(A)$ as well as after the ID codes were released $(B)$. Representative immunoblots are shown, probed with $S 897$ NR1 antibody (1:1000), anti-NR1 antibody (1:1000), S831 GluR1 antibody (1:1000), S845 GluR1 antibody (1:1000), S380 PTEN antibody (1:2000), and anti-tubulin (1:1000). In all cases, graphs represent the means and SEs of optical densities reflecting the corrected S897 to total NR1 levels.

results obtained from the Stanley Consortium and MRC tissues. In summary, there were no significant correlations between the S897/total NR1 and any of the variables tested (see supplemental Tables 1 and 2, available at www.jneurosci.org). To further control for global nonspecific effects on phosphorylation, we also ascertained the stability of the phosphorylated forms of two additional proteins that are involved in cellular signaling. First, we ascertained the phosphorylation status of a cell surface receptor, the AMPA glutamate receptor GluR1, which is regulated by CaMKII (calcium-calmodulin-dependent kinase II)- or protein kinase C (PKC)-mediated phosphorylation at S831, as well as by PKA-mediated phosphorylation at S845 (Roche et al., 1996). Second, we ascertained the phosphorylation status of an intracellular protein, the tumor suppressor phosphatase PTEN, which modulates phosphatidylinositol 3-kinase signaling and is regulated through phosphorylation at S380 (Birle et al., 2002). In contrast to the dramatic decrease in phosphorylation levels of NR1 at S897, immunoblot experiments using phospho-specific antibodies against these three control sites did not reveal any significant differences in the levels of phosphorylation in either frontal cortex or hippocampus of controls and patients with schizophrenia (Figs. $1 B, C, 2 B$ ).

\section{Discussion}

NMDA receptor function is mediated by specific activation and modulation of the receptor subunits by several ligands in addition to glutamate itself. Protein phosphorylation is an important mechanism for the regulation of NMDA receptor function (Bading and Greenberg, 1991). The present results show a highly significant decrease in the phosphorylation levels of the NR1 subunit of the NMDA receptor at $\mathrm{S} 897$ in the frontal cortex and hippocampus of patients affected with schizophrenia. Future experiments will address the phosphorylation status at additional NR1 regulatory phosphoresidues, such as the PKC-phosphorylated S896. Unfortunately, currently available S896 phospho-specific antibodies produce, in our hands, nonspecific signal when used in immunoblots from human brain tissues (data not shown).

It is not clear how phosphorylation at S897 modulates the NMDA receptor activity, although preliminary experiments argued against an effect on receptor clustering (Tingley et al., 1997). It is possible that under-phosphorylation of S897 alters NMDA receptor activity by decreasing its sensitivity to glutamate or increasing its sensitivity to antagonists (Maldve et al., 2002) or by inactivating downstream signal transduction pathways. These may include downstream transcriptional cascades, because S897 is critically involved in the expression of NMDA receptor effects on D1 (dopamine receptor 1)-mediated cAMP response element-binding protein phosphorylation (Rajadhyaksha et al., 1999). This hypofunction of NMDA-mediated signaling-synaptic plasticity may be contributing to the development of the clinical syndrome. In the absence of any common coding sequence variants that could affect S897 phosphorylation levels, the nature of the upstream signals that lead to S897 underphosphorylation remains to be elucidated and may include, for example, mutations in other receptors or signaling molecules modulating relevant kinase-phosphatase pathways including the DARPP-32 (dopamine- and cAMP-regulated phospho-protein of $32 \mathrm{kDa}$ ) pathway (Snyder et al., 1998) and the recently implicated calcineurin pathway (Gerber et al., 2003; Miyakawa et al., 2003).

Although NMDA S897 under-phosphorylation appears to be consistent in two independent samples of patients with schizophrenia, it is generally difficult to draw inferences about receptor activity by studying receptor modification in affected brains. A decrease in receptor phosphorylation may be interpreted as a molecular response to increased receptor activity or, conversely, as a cause of decreased receptor function. Nevertheless, taken together with previous findings (Leveque et al., 2000), our results are consistent with the latter interpretation, as well as with a model in which antipsychotic drugs decrease disease symptoms and improve cognition, at least partly, by facilitating phosphorylation of the NR1 subunit at the under-phosphorylated S897. Whether abnormal phosphorylation of NMDA receptors is the cumulative end result of several genetic and epigenetic events that contribute to the development of schizophrenia remains to be determined, and generation of animal models of the underphosphorylated state of NMDA receptors will be invaluable toward this end. 


\section{References}

Bading H, Greenberg ME (1991) Stimulation of protein tyrosine phosphorylation by NMDA receptor activation. Science 253:912-914.

Birle D, Bottini N, Williams S, Huynh H, deBelle I, Adamson E, Mustelin T (2002) Negative feedback regulation of the tumor suppressor PTEN by phosphoinositide-induced serine phosphorylation. J Immunol 169:286-291.

Gerber DJ, Hall D, Miyakawa T, Demars S, Gogos JA, Karayiorgou M, Tonegawa S (2003) Evidence for association of schizophrenia with genetic variation in the 8p21.3 gene, PPP3CC, encoding the calcineurin gamma subunit. Proc Natl Acad Sci USA 100:8993-8998.

Goff DC, Tsai G, Levitt J, Amico E, Manoach D, Schoenfeld DA, Hayden DL, McCarley R, Coyle JT (1999) A placebo-controlled trial of D-cycloserine added to conventional neuroleptics in patients with schizophrenia. Arch Gen Psychiatry 56:21-27.

Heresco-Levy U, Javitt DC, Ermilov M, Mordel C, Silipo G, Lichtenstein M (1999) Efficacy of high-dose glycine in the treatment of enduring negative symptoms of schizophrenia. Arch Gen Psychiatry 56:29-36.

Javitt DC, Zukin SR (1991) Recent advances in the phencyclidine model of schizophrenia. Am J Psychiatry 148:1301-1308.

Kilts CD (2001) The changing roles and targets for animal models of schizophrenia. Biol Psychiatry 50:845-855.

Leveque J-C, Macias W, Rajadhyaksha A, Carlson RR, Barczak A, Kang S, Li X-M, Coyle JT, Huganir RL, Heckers S, Konradi C (2000) Intracellular modulation of NMDA receptor function by antipsychotic drugs. J Neurosci 20:4011-4020.

Maldve RE, Zhang TA, Ferrani-Kile K, Schreiber SS, Lippmann MJ, Snyder GL, Fienberg AA, Leslie SW, Gonzales RA, Morrisett RA (2002) DARPP-32 and regulation of the ethanol sensitivity of NMDA receptors in the nucleus accumbens. Nat Neurosci 5:641-648.

Meador-Woodruff JH, Healy DJ (2000) Glutamate receptor expression in schizophrenic brain. Brain Res Brain Res Rev 31:288-294.
Miyakawa T, Leiter LM, Gerber DJ, Gainetdinov RR, Sotnikova TD, Zeng H, Caron MG, Tonegawa S (2003) Conditional calcineurin knockout mice exhibit multiple abnormal behaviors related to schizophrenia. Proc Natl Acad Sci USA 100:8987-8992.

Rajadhyaksha A, Barczak A, Macias W, Leveque JC, Lewis SE, Konradi C (1999) L-Type $\mathrm{Ca}(2+)$ channels are essential for glutamate-mediated CREB phosphorylation and c-fos gene expression in striatal neurons. J Neurosci 19:6348-6359.

Roche KW, O’Brien RJ, Mammen AL, Bernhardt J, Huganir RL (1996) Characterization of multiple phosphorylation sites on the AMPA receptor GluR1 subunit. Neuron 16:1179-1188.

Schiffer HH (2002) Glutamate receptor genes: susceptibility factors in schizophrenia and depressive disorders? Mol Neurobiol 25:191-212.

Snyder GL, Fienberg AA, Huganir RL, Greengard P (1998) A dopamine/D1 receptor/protein kinase A/dopamine- and cAMP-regulated phosphoprotein $\left(M_{\mathrm{r}} 32 \mathrm{kDa}\right) /$ protein phosphatase-1 pathway regulates dephosphorylation of the NMDA receptor. J Neurosci 18:10297-10303.

Swope SL, Moss SJ, Raymond LA, Huganir RL (1999) Regulation of ligandgated ion channels by protein phosphorylation. Adv Second Messenger Phosphoprotein Res 33:49-78.

Thaker G, Carpenter Jr WT (2001) Advances in schizophrenia. Nat Med 7:667-671.

Tingley WG, Ehlers MD, Kameyama K, Doherty C, Ptak JB, Riley CT, Huganir RL (1997) Characterization of protein kinase A and protein kinase C phosphorylation of the N-methyl-D-aspartate receptor NR1 subunit using phosphorylation site-specific antibodies. J Biol Chem 272:5157-5166.

Torrey F, Webster M, Knable M, Johnston N, Yolken RH (2000) The Stanley Foundation brain collection and neuropathology consortium. Schizophrenia Res 44:151-155.

Tsai G, Yang P, Chung LC, Lange N, Coyle JT (1998) D-serine added to antipsychotics for the treatment of schizophrenia. Biol Psychiatry 44: 1081-1089. 